CDD: 193

\title{
A CARACTERIZAÇÃO DA LÓGICA PELA FORÇA ASSERTÓRICA EM FREGE. RESPOSTA A MARCO RUFFINO
}

\author{
DIRK GREIMANN
}

Departamento de Filosofia

Universidade Federal Fluminense

Rua Professor Marcos Waldemar de Freitas Reis, Bloco O

São Domingos

24210-350, NITERÓI - RJ

BRASIL

greimann@dirk-greimann.de

Received: 06.02.201I; Accepted: 18.05.201I

\begin{abstract}
Resumo: Segundo a caracterização padrão da lógica nos escritos fregeanos, a palavra "verdadeiro" indica a essência da lógica, assim como a palavra "bom" indica a essência da ética e a palavra "belo" a essência da estética. Num escrito póstumo de 1915, porém, Frege afirma que é a força assertórica, e não a palavra "verdadeiro", que indica a essência da lógica. Prima facie, esta correção está em conflito com a crítica fregeana à concepção psicologista da lógica. Pois, segundo esta crítica, a lógica não é a ciência das leis "do ser tomado como verdadeiro", mas a ciência das leis "do ser verdadeiro", ao passo que a força assertórica expressa o ser tomado como verdadeiro. Em escritos anteriores, tentei resolver este conflito por uma reconstrução da concepção fregeana da verdade baseada na tese fregeana de que verdade é expressa na linguagem natural pela "forma da sentença assertórica". A meta do presente trabalho é defender esta interpretação contra as objeções recentemente feitas por Marco Ruffino.
\end{abstract}

Palavras-chave: Frege. Essência da lógica. Verdade. Força assertórica.

\section{FREGE'S CHARACTERISATION OF LOGIC IN TERMS OF ASSERTORIC FORCE}

\begin{abstract}
According to the standard characterization of logic in Frege's writings, the word "true" indicates the essence of logic, as the word "good" indicates the essence of ethics and the word "beautiful" the essence of aesthetics. In a posthumous writing from 1915, however, Frege says that it is the assertoric force, and not the word "true", which indicates the essence of logic properly. Prima facie, this correction is in conflict with Frege's criticism of the psychologist conception of logic. For according to this
\end{abstract}

Manuscrito - Rev. Int. Fil., Campinas, v. 35, n. 1, p. 61-83, jan.-jun. 2012. 
criticism, logic is not the science of the laws of "being taken as true", but the science of the laws of "being true", while the assertoric force expresses being taken as true. In previous writings, I tried to resolve this conflict by a reconstruction of Frege's conception of truth that is based on his thesis that truth is expressed in natural language by the "form of the assertoric sentence". The goal of this paper is to defend this interpretation against the objections recently made by Marco Ruffino.

Keywords: Frege. Essence of logic. Truth. Assertoric force.

\section{Introdução}

Frege inicia a sua exposição da lógica freqüentemente com uma introdução cuja tarefa principal consiste em caracterizar a "natureza" ou "essência" desta disciplina. ${ }^{1}$ Neste contexto, ele afirma que a palavra "verdadeiro" indica a essência da lógica, assim como a palavra "bom" indica a essência da ética e a palavra "belo" a essência da estética. Num escrito póstumo de 1915, porém, ele parece corrigir esta tese, afirmando que a palavra "verdadeiro" faz meramente "uma tentativa frustrada de indicar a essência da lógica, uma vez que aquilo que de fato está em jogo não está, de maneira alguma, na palavra "verdadeiro", mas sim na força assertórica com a qual a sentença é afirmada" (Frege, 1983, pp. 271-2).

Prima facie, esta correção está em conflito com a crítica fregeana à concepção psicologista da lógica. A força assertórica com a qual usualmente proferimos uma sentença assertórica expressa que tomamos o conteúdo proposicional desta sentença como verdadeiro. Consequentemente, a caracterização da lógica pela força assertórica sugere que a lógica seja a ciência das leis do ser tomado como verdadeiro. Mas, na sua crítica ao psicologismo (ou "idealismo"), Frege critica esta concepção da lógica explicitamente, argumentando que as leis do ser tomado como verdadeiro são leis psicológicas que não podem ser usadas para o fim da lógica de justificar conclusões. Para

${ }^{1}$ Este trabalho foi escrito com apoio do CNPq. Agradeço a Abílio Rodrigues (UFMG) pelos seus comentários muito úteis.

Manuscrito - Rev. Int. Fil., Campinas, v. 35, n. 1, p. 61-83, jan.-jun. 2012. 
Frege, a lógica não é a ciência das leis do ser tomado como verdadeiro, mas a ciência das leis do ser verdadeiro. ${ }^{2}$

No meu livro (2003) e escritos relacionados, tentei resolver este conflito por uma reconstrução da concepção fregeana da verdade como uma "teoria assertórica da verdade" que se baseia na tese fregeana de que a verdade é aquilo que é expresso na linguagem natural através da "forma da sentença assertórica". ${ }^{3}$ A meta do presente trabalho é defender esta interpretação contra as objeções feitas en passant por Marco Ruffino no seu artigo "O Verdadeiro, o Bom e o Belo em Frege" de 2006. O seu ponto principal é que não fica muito claro, na minha apresentação, o que poderia ser uma teoria nestes moldes e, em particular, se uma teoria assertórica da verdade seria, no final das contas, uma teoria sobre o reconhecimento da verdade que expressamos pela força assertórica (cf. Ruffino, 2006, p. 39).

No presente trabalho elaboro a minha interpretação. A primeira seção contém uma explicação do conceito fregeano de força assertórica. A segunda seção descreve o papel da força assertórica na lógica fregeana. A terceira seção é dedicada à reconstrução do conceito fregeano de verdade. A quarta seção ocupa-se, finalmente, com a caracterização fregeana da essência da lógica pela força assertórica.

\section{Força assertórica}

Pelo proferimento de uma sentença assertórica usualmente se faz uma asserção. Mas às vezes tais sentenças são proferidas sem fazer uma asserção. Uma testemunha na audiência, por exemplo, profere sentenças assertóricas para fazer asserções. Um ator no palco, em contrapartida, profere tais sentenças sem fazer asserções; ele esta

${ }^{2}$ Cf. Frege (1918a, p. 343 e 1893, p. XVI).

${ }^{3}$ Greimann (2003, 2004, e 2005).

Manuscrito - Rev. Int. Fil., Campinas, v. 35, n. 1, p. 61-83, jan.-jun. 2012. 
fazendo "pseudo-asserções" (Frege, 1918a, p. 347, e 1983, p. 142), ou seja, ele está meramente fingindo fazer asserções. Um dado proferimento tem força assertórica, no sentido de Frege se, e somente se, por este proferimento o falante está realmente fazendo uma asserção. Ter força assertórica significa efetuar uma asserção genuína (cf. Frege, 1918a, pp. 346-347).

Quando proferimos uma sentença com força assertórica, estamos apresentando o seu conteúdo proposicional como verdadeiro, como um fato. Quando fazemos uma asserção sabendo que o seu conteúdo é falso, estamos mentindo (cf. Frege, 1983, p. 252). Mas isto não se aplica ao ator no palco, porque as suas asserções não são asserções genuínas, mas pseudo-asserções (cf. Frege, 1983, pp. 142, 214, 252).

Para apresentar um conteúdo como verdadeiro, não precisamos do predicado "verdadeiro", mas somente da força assertórica (cf. Frege, 1983, p. 251f.). Mesmo quando usamos esta palavra, como em "É verdade que a neve é branca", aquilo que efetua a atribuição da verdade ao pensamento expresso não é esta palavra, mas a força assertórica com a qual proferimos esta sentença. Em particular, o uso da palavra "verdadeiro" não pode substituir a força assertórica. Assim, um ator no palco não pode restituir a força assertórica por usar "É verdade que a neve é branca" em lugar de "A neve é branca" (cf. Frege, 1983, p. 251f.).

Da mesma maneira que a quantificação, a asserção tem um domínio (Gebiet) ao qual a força assertórica se estende. Na sentença complexa

(1) Se a neve é preta, então ela não é branca, a sentença

(2) A neve é preta

ocorre como sentença subordinada. Quando proferimos (1) com força assertórica, estamos expressando também o pensamento contido em (2), mas não estamos afirmando este pensamento porque ele não está 
no domínio da asserção. Caso contrário, a asserção de (1) não seria verdadeira, mas falsa (cf. Frege, 1983, p. 215).

A ocorrência de (2) em (1) mostra que podemos expressar um pensamento falso sem fazer uma asserção errada (cf. Frege, 1983, pp. 150, 192, 201, 214). A asserção de (1) seria errada somente se o pensamento expresso por (2) fosse incluído no domínio da força assertórica.

A linguagem natural não contém um signo próprio para a força assertórica, destaca Frege (cf. Frege, 1983, pp. 183, 214, 201). O meio lingüístico principal para efetuar uma asserção consiste naquilo que Frege chama da "forma da sentença assertórica", isto é, o conjunto das propriedades sintáticas pelo qual sentenças assertóricas são distinguidas das sentenças interrogativas (como: “A neve é preta?”) e das sentenças imperativas (como: "Diga a verdade!"). Na maioria dos contextos, o uso desta forma constitui uma asserção. ${ }^{4}$

$\mathrm{Na}$ sua linguagem ideal, Frege introduz um signo próprio para a asserção. Uma sentença assertórica dessa linguagem sempre tem a forma " $\mid$ - p". A barra vertical, que é chamada de "barra de juízo", é um operador ilocucionário cuja tarefa é representar a força assertórica. Esta barra corresponde à forma da sentença assertórica na linguagem natural. A barra horizontal é chamada no primeiro sistema de Frege de "barra de conteúdo" e no segundo sistema simplesmente de "Horizontal". No primeiro sistema, que é descrito na Begriffsschrift (1879), ainda falta a distinção entre sentido e referência, que é a marca do segundo sistema, descrito nas Grundgesetze (1893). ${ }^{5}$

Para determinar exatamente o que Frege entende por "força assertórica", temos que reconstruir o conceito fregeano de asserção e a interpretação da barra de juízo no primeiro e no segundo sistema.

4 Por esta razão, as sentenças desta forma se chamam de "sentenças assertóricas". Um contexto no qual podemos usar esta forma sem fazer uma asserção é o palco.

${ }^{5}$ Uma exposição detalhada de ambos os sistemas é dada em Greimann (2000).

Manuscrito - Rev. Int. Fil., Campinas, v. 35, n. 1, p. 61-83, jan.-jun. 2012. 


\subsection{O conceito fregeano de asserção}

$\mathrm{Na}$ primeira investigação lógica, em "Der Gedanke" (1918), Frege dá uma definição informal de asserção. $O$ ponto de partida é a sua distinção entre dois atos cognitivos que ele chama de "pensar" e "julgar". Quando formamos uma hipótese e deixamos em aberto se ela é verdadeira ou falsa, estamos realizando um ato de pensar. Este ato é realizado, por exemplo, quando estamos nos perguntando "Será que existe matéria escura?". $\mathrm{O}$ ato de julgar é definido por Frege como o "reconhecimento da verdade de um pensamento". Ele consiste na formação de uma crença. Quando, por exemplo, reconhecemos o pensamento que existe matéria escura como verdadeiro, então estamos formando a crença (ou "convicção") de que existe matéria escura. Segundo Frege, o julgar desempenha um papel essencial na aquisição de saber: pensar que p é meramente uma condição necessária, mas não suficiente, para saber que p. ${ }^{6}$

De acordo com a explicação em "Der Gedanke" e vários outros escritos de Frege, o ato de asserção consiste na "manifestação" ou "comunicação" (Kundgebung, Verlautbarung) de um ato de julgar. ${ }^{7}$ Pela asserção que a neve é branca, por exemplo, o falante está expressando o seu reconhecimento da verdade do pensamento que a neve é branca (cf. Frege, 1983, pp. 150, 183). Esta concepção, que podemos chamar de "concepção psicologista", implica que os atos assertóricos fazem parte dos atos expressivos como "hum!" e "que nojo!", que servem para expressar atitudes psicológicas. A única diferença é que por um ato expressivo comum como "hum!" expressamos um sentimento, ao passo que por um ato assertórico expressamos uma atitude proposicional, a saber, uma crença.

${ }^{6}$ Cf. Frege (1918a, pp. 345-347). Uma reconstrução encontra-se em Greimann (2004).

${ }^{7}$ Cf. Frege (1918a, p.346 e 1983 pp. 150, 183, 201, 214).

Manuscrito - Rev. Int. Fil., Campinas, v. 35, n. 1, p. 61-83, jan.-jun. 2012. 
Todavia, nos textos de Frege encontra-se também uma "concepção lógica" da asserção de acordo com a qual o ato de asserção consiste na "apresentação" de um pensamento "como verdadeiro" (als wahr hinstellen), ou na "afirmação de um pensamento como verdadeiro" (als wahr behaupten). ${ }^{8}$ Quando, por exemplo, afirmamos que a neve é branca, estamos apresentando o pensamento de que a neve é branca como verdadeiro. Pela pergunta se a neve é branca expressamos o mesmo pensamento, mas sem apresentá-lo como verdadeiro. A pergunta contém o pedido ao ouvinte de determinar o valor de verdade do pensamento expresso (pela resposta "sim" ou "não"), e a asserção contem a afirmação de que este valor é o Verdadeiro (cf. Frege, 1918a, p. 346 e 1918b, p. 362).

Segundo a concepção psicologista, pelo proferimento da sentença "A neve é branca" com força assertórica o falante expressa que ele acredita que a neve é branca. Para fazer isto explícito, poderíamos parafrasear "A neve é branca" por "Eu acredito que a neve é branca". A forma da sentença assertórica é um operador psicológico cuja tarefa consiste em indicar que o falante toma o pensamento expresso como verdadeiro. De acordo com a concepção lógica, por outro lado, o falante expressa pelo proferimento da sentença "A neve é branca" com força assertórica que o pensamento expresso é verdadeiro. Para tornar isso explícito, poderíamos parafrasear esta sentença por "É verdade que a neve é branca". Desta perspectiva, a forma da sentença assertórica é um operador lógico que serve para apresentar um conteúdo como verdadeiro.

${ }^{8}$ Cf. (Frege 1918a, p. 35, 1918b, pp. 54, 64, 66, e 1983, pp. 54, 58, 192, 214, 251f).

Manuscrito - Rev. Int. Fil., Campinas, v. 35, n. 1, p. 61-83, jan.-jun. 2012. 


\subsection{A função da barra de juízo}

De acordo com Wittgenstein, “|_-” é logicamente não relevante, porque na obra de Frege (e Russell) este signo simplesmente indica que estes autores tomam as proposições marcadas com este signo como verdadeiro (cf. Wittgenstein, 1921, sentença 4.442). Segundo esta interpretação, a barra de juízo (ou o signo mais complexo “|-_") é um operador psicológico cuja função lingüística é expressar certas atitudes proposicionais. Dummett tem uma leitura semelhante desta barra. Ele atribui a Frege uma concepção da asserção segundo a qual a asserção é "a expressão eterna do ato interior de adotar uma atitude mental particular" (cf. Dummett, 1973, p. 311). De acordo com esta interpretação, a barra de juízo serve também para marcar as proposições que o falante ou autor toma como verdadeiras.

Podemos, porém, mostrar que no, primeiro lugar, a barra de juízo é um operador de verdade, e não um operador psicológico: a sua tarefa é expressar que a proposição expressa é verdadeira, e não que o falante toma ou julga esta proposição como verdadeira. Isto fica claro pelos seguintes fatos. ${ }^{9}$

[i] Nos escritos da sua primeira fase, que é caracterizada pela falta da distinção entre sentido e referência, Frege diz explicitamente que "|" é usada no seu sistema como um meio para "apresentar um conteúdo como verdadeiro" (als wabr hinstellen), e que uma sentença da forma " $\mid-\Delta$ " expressa que o conteúdo - $\Delta$ "é um fato" (Tatsache) (cf. Frege, 1879, \3, e 1983, p. 58).

[ii] Nos escritos mais tardios, ele explicitamente diz que, no seu sistema revisado, uma sentença da forma " $\mid-\Delta$ " expressa que o valor de verdade — $\Delta$ “é o Verdadeiro”. Em “Funktion und Begriff” (1891), por exemplo, ele explicita a diferença entre pares de instancias como " $\mid$ - Prime(3)" e "— Prime(3)" da seguinte maneira: ao escrever " $\mid$ Prime(3)", não estamos somente escrevendo um valor de verdade,

${ }^{9}$ Para uma exposição mais detalhada, veja Greimann (2000).

Manuscrito-Rev. Int. Fil., Campinas, v. 35, n. 1, p. 61-83, jan.-jun. 2012. 
como em "- Prime(3)", mas simultaneamente estamos dizendo que este valor "é o Verdadeiro" (cf. Frege 1891, pp. 136-137).

Similarmente, em Grundgesetze, Frege explica que ao escrever uma instância de "— $\Delta$ ", estamos meramente "designando" (bežeichnen) um valor de verdade, sem dizer se este valor é o Verdadeiro ou o Falso

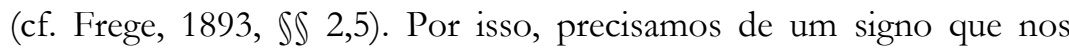
permita "afirmar algo como verdadeiro" (cf. \5). Esta é a tarefa da barra de juízo: ao colocar esta barra em frente de um nome de um valor de verdade (como "- Prime(3)"), convertemos este nome numa sentença assertórica pela qual afirmamos que este nome se refere ao Verdadeiro (durch einen solchen Satz, wird behauptet, dass dieser Name das Wabre bedeute) (cf. \32). Como tal nome expressa ao mesmo tempo um pensamento, temos em toda sentença assertórica da linguagem formal "um juízo de que um pensamento é verdadeiro" (cf. \32).

Estas explanações sugerem muito fortemente que a barra de juízo é, em primeiro lugar, um operador de verdade cuja função expressiva principal consiste em expressar a verdade de um pensamento. No primeiro sistema, a barra vertical em " $\mid-\Delta$ " expressa que o conteúdo julgável $-\Delta$ "é um fato", e no segundo sistema que o valor de verdade - $\Delta$ "é o Verdadeiro".

[iii] A contrapartida da barra de juízo na linguagem natural é a "forma da sentença assertórica". De acordo com Frege, esta forma é o meio principal da linguagem natural para predicar verdade de um conteúdo proposicional. Num fragmento intitulado "Logik" de 1897, ele escreve:

É usando a forma da sentença assertórica que expressamos a verdade, e para fazer isto, nós não precisamos da palavra "verdadeiro". De fato, podemos dizer que mesmo quando usamos a expressão "é verdadeiro que...", a coisa essencial é realmente a forma da sentença assertórica. (Frege 1983, p. 140) ${ }^{10}$

${ }^{10}$ Cf. também Frege (1983, pp. 251-2).

Manuscrito - Rev. Int. Fil., Campinas, v. 35, n. 1, p. 61-83, jan.-jun. 2012. 
Suponhamos, por exemplo, que queremos expressar a verdade do conteúdo que a neve é branca. Segundo Frege, isso pode ser alcançado simplesmente pelo uso da sentença "A neve é branca". Em virtude da sua forma assertórica, essa sentença expressa (em contextos normais) a verdade de que a neve é branca. A sentença interrogativa "A neve é branca?" também expressa que a neve é branca, mas ela não expressa que isto é verdadeiro. Como a forma da sentença assertórica é considerada por Frege como um operador de verdade, o mesmo aplicase à barra de juízo também.

[iv] Numa carta, Jourdain pergunta a Frege se ele "considera a asserção (|-) como algo meramente psicológico" (Frege, 1976, p. 126). A resposta de Frege é a seguinte:

Com certeza o julgar (o reconhecer algo como verdadeiro) é um acontecimento mental interior; mas que algo é verdadeiro, é independente daquele que reconhece (Erkennenden), é objetivo. Quando afirmo algo como verdadeiro (als wahr behaupte), não quero falar de mim, de um acontecimento na minha alma. E para entendê-lo (um es zu verstehen), não se precisa saber quem o afirma (wer es behauptet). (Frege 1976, pp. 126f.)

Frege parece criticar aqui a concepção psicologista da asserção. A sua objeção é que pela asserção que $\mathrm{p}$ o falante não quer falar do acontecimento mental do julgar que $\mathrm{p}$ na sua alma. Ele não quer dizer que ele toma o conteúdo que $\mathrm{p}$ como verdadeiro, mas que este conteúdo de fato é verdadeiro. Para entender "Eu acredito que p", precisamos saber quem está afirmando esta sentença, mas para entender "É verdade que p", não precisamos saber isto.

\subsection{Os constituintes da força assertórica}

Segundo Marco Ruffino, a força assertórica no sentido de Frege consiste na "expressão de nosso assentimento" (Ruffino, 2006, p. 41); ela é nada mais que "a aprovação ou assentimento de quem contempla um pensamento (p. 38). Esta interpretação combina-se muito bem com 
a caracterização psicologista da asserção, que é a caracterização padrão nos escritos do Frege. Mas ela ignora a caracterização lógica, segundo a qual esta força é mais que a expressão de nosso assentimento; ela contém, como constituinte essencial, a apresentação de um pensamento como verdadeiro.

Para levar isto em conta, parece-me mais adequado reconstruir a força assertórica como uma propriedade complexa que contém tanto um aspecto psicológico como um aspecto lógico, sendo o aspecto lógico a apresentação do pensamento como verdadeiro e o aspecto psicológico a manifestação do ato interior do reconhecimento do pensamento como verdadeiro. Nota-se que a concepção psicologista e a concepção lógica da asserção não são incompatíveis, mas podem ser consideradas como complementares; pois, ao asserir que p, o falante está expressando simultaneamente que ele acredita que p e que é um fato que p.

\section{O papel da força assertórica no sistema fregeano}

$\mathrm{Na}$ atualidade, dificilmente encontramos manuais lógicos que contêm um capítulo sobre a força assertórica. Qual a relevância da força assertórica para a lógica, segundo Frege? Quais os seus motivos para representar esta força por um signo próprio na sua linguagem formal? Precisamos responder a estas perguntas para entender a sua tese de que é a força assertórica que indica a essência da lógica.

Dummett considera a lógica fregeana primeiramente como uma teoria do significado lingüístico (Dummett 1973, pp. 669, 675). Desta perspectiva, a visualização da força assertórica na linguagem formal é motivada, em primeiro lugar, pelo insight de que o significado lingüístico de uma sentença não pode ser identificado com o seu conteúdo proposicional, porque o significado pragmático da sentença é um componente essencial adicional do seu significado lingüístico. Para entender, por exemplo, o significado lingüístico da sentença interrogativa "A neve é branca?", não é suficiente saber qual conteúdo 
proposicional ela expressa; é necessário também saber que ela é normalmente proferida com a intenção de fazer uma pergunta.

Portanto, uma teoria completa do significado tem que levar o significado pragmático em conta. Para apresentar o significado lingüístico de uma dada sentença corretamente, é necessário tornar o componente pragmático visível. Esta é a função da barra de juízo. ${ }^{11}$

É controverso, porém, se a lógica fregeana pode ser concebida como uma teoria do significado lingüístico. De qualquer forma, a visualização da força assertórica é relevante, em primeiro lugar, para outras partes da lógica fregeana, a saber, a teoria da inferência lógica e a teoria da forma lógica dos juízos.

[i] Segundo Frege, a visualização da força assertórica desempenha um papel essencial na apresentação adequada das inferências lógicas. Ele alega que "meras hipóteses" (blosse Hypothesen) não podem ser usadas como premissas numa inferência, ou seja, exclusivamente asserções podem servir como premissas. Na carta a Jourdain já mencionada, ele destaca o papel essencial que a barra de juízo desempenha neste contexto:

Aquilo que supostamente serve como premissa de uma inferência deve ser verdadeiro. Quando, de acordo com isso, apresenta-se uma inferência, deve-se proferir (aussprechen) as sentenças de premissas (Prämissensätze) com força assertórica; pois a verdade das premissas é essencial para a correção (Richtigkeit) da inferência. Se se omitisse na apresentação de uma inferência a barra de juízo, faltaria alguma coisa essencial. (Frege 1976, p. 127)

${ }^{11} \mathrm{Na}$ linguagem natural, as sentenças são pragmaticamente ambíguas, porque elas são proferidas ora com e ora sem força assertórica. Do ponto de vista da lógica, esta ambigüidade é um defeito, pois numa linguagem logicamente perfeita sempre deveria ser claro se uma sentença proferida tem ou não tem força assertórica. Para eliminar a ambigüidade das sentenças precisamos introduzir um signo próprio cuja ocorrência determina se uma sentença tem força assertórica ou não. Segundo Dummett (1981, p. 492), Frege introduz a barra de juízo na sua linguagem ideal também por este motivo.

Manuscrito - Rev. Int. Fil., Campinas, v. 35, n. 1, p. 61-83, jan.-jun. 2012. 
Do ponto da vista da lógica atual, esta concepção parece estranha, por duas razões. Primeiro, é perfeitamente possível derivar conclusões validamente de premissas falsas. Da premissa falsa "A neve é preta", por exemplo, podemos derivar validamente a conclusão "Algo é preto". Logo, a validade de uma inferência não depende da verdade das premissas. Segundo, para fazer uma inferência não é necessário afirmar as premissas; meras hipóteses podem ser usadas como premissas numa inferência. Quando derivamos uma conclusão $C$ das premissas $\mathrm{P}_{1}$ a $\mathrm{P}_{\mathrm{n}}$, estamos afirmando que a conclusão não pode ser falsa se as premissas são todas verdadeiras, mas não estamos afirmando nem a conclusão $C$ nem as premissas $P_{1}$ a $P_{n}$.

Porque Frege insiste na verdade e na asserção das premissas? A resposta mais plausível é que ele entende por "inferência" ou "derivação" (Schluss) uma espécie de justificação. ${ }^{12}$ Num fragmento sobre lógica publicado postumamente, Frege explica o conceito de derivação lógica da seguinte maneira:

As razões (Gründe), que ora (nun) justificam o reconhecimento de uma verdade, baseiam-se (liegen in) freqüentemente em outras verdades já reconhecidas. (...) A lógica tem a ver somente com tais razões de julgar (Gründen des Urteilens) que são verdades. Julgar, ao estar consciente de outras verdades com razões de justificação (Rechtfertigungsgründen), se chama inferir. Há leis sobre este tipo de justificação, e estabelecer (aufzustellen) estas leis é a meta da lógica. (Frege 1983, p. 3)

"Justificar" a conclusão C significa demonstrar a verdade de C. E "inferir" a conclusão C significa justificar $C$ por razões que já foram reconhecidas como verdades. Obviamente, não podemos justificar corretamente a conclusão por premissas falsas. Por premissas falsas não podemos justificar nenhuma conclusão. Logo, as premissas devem ser verdadeiras. Além disso, quando queremos justificar a conclusão, não

$12 \mathrm{Na}$ linguagem natural usamos "prova" neste sentido. Uma prova com premissas falsas não prova nada.

Manuscrito - Rev. Int. Fil., Campinas, v. 35, n. 1, p. 61-83, jan.-jun. 2012. 
podemos deixar o valor de verdade das premissas em aberto; precisamos afirmar as premissas como verdadeiras.

Propriamente dito, o que justificamos por uma derivação lógica não é um pensamento - a conclusão -, mas o nosso reconhecimento de um pensamento como verdadeiro, ou seja, a nossa asserção da conclusão. Quando derivamos a conclusão $\mathrm{C}$ das premissas $\mathrm{P}_{1}$ a $\mathrm{P}_{\mathrm{n}}$, não estamos afirmando somente que a conclusão é verdadeira se as premissas $P_{1}$ a $P_{n}$ são verdadeiras, mas estamos afirmando também as premissas e a conclusão. Para tornar isto explícito, precisamos de novo visualizar a força assertórica na linguagem formal.

[ii] $\mathrm{Na}$ teoria fregeana dos juízos, a barra do juízo serve para tornar a forma lógica dos juízos transparente. Segundo Frege, na linguagem natural as sentenças assertóricas são usadas para dois fins logicamente independentes: para o fim de meramente expressar um pensamento e para o fim de asserir um pensamento como verdadeiro. Se tal sentença ocorre enquanto sentença subordinada numa sentença complexa, como em

(1) Se a neve é preta, então a neve não é branca,

ela é usada meramente para o primeiro fim, mas se ela ocorre sozinha, como em

(2) A neve é preta, ela é usada para expressar um pensamento e asseri-lo simultaneamente como verdadeiro. Do ponto da vista da teoria fregeana do juízo, esta propriedade da linguagem natural é logicamente enganadora, por duas razões:

Primeiro, ela obscurece a estrutura lógica de juízos expressos por sentenças complexas. Como, por exemplo, a sentença condicional (1) é composta de duas sentenças assertóricas que, quando ocorrem sozinhas, expressam juízos, a estrutura sintática da sentença complexa apresenta o juízo expresso como um juízo complexo composto dos juízos expressos por "a neve é preta" e "a neve não é branca". $\mathrm{Na}$ verdade, porém, a sentença complexa não expressa dois juízos, mas um único juízo cujo conteúdo é complexo (cf. Frege, 1983, p. 215, e 1976, 
p. 73). Para resolver este problema, precisamos de um operador que marque o domínio da força assertórica. A barra de juízo é tal marcador (cf. Frege, 1879, \2).

Segundo, a sintaxe da linguagem natural provoca uma confusão de propriedades do ato de julgar com propriedades dos conteúdos de juízos. Na lógica kantiana, por exemplo, a negação é concebida como um ato de julgar ("atos do entendimento") que constitui o pólo oposto da afirmação. Segundo esta abordagem, a diferença entre um juízo negativo e um juízo afirmativo é uma diferença no ato realizado pelo entendimento. Ao julgar que a neve é branca, estamos afirmando o conteúdo que a neve é branca, e ao julgar que a neve não é branca, estamos negando o mesmo conteúdo. Desta perspectiva, a negação é um modo de julgar. No parágrafo 4 da Begriffsschrift, a concepção kantiana é criticada por Frege, sem mencionar Kant. ${ }^{13}$ De acordo com Frege, todos os juízos têm o mesmo modo: na terminologia kantiana, todos os juízos são juízos afirmativos. A negação não é um modo de julgar, mas uma parte do conteúdo dos juízos negativos. $\mathrm{O}$ ato realizado no caso do juízo de que a neve não é branca é idêntico ao ato realizado no caso do juízo que a neve é branca; em ambos os casos, reconhecemos a verdade de um pensamento. Conseqüentemente, a negação pertence ao conteúdo do juízo, não ao ato de julgar, Frege argumenta.

Para tornar a forma lógica dos juízos negativos sintaticamente explícita, Frege precisa construir uma notação que torne visível que a negação não é um modo de julgar, mas uma parte do conteúdo de juízos. Para tanto, ele representa, no seu primeiro sistema, o ato realizado pelo entendimento pela barra de juízo, e o conteúdo pela barra de conteúdo. De acordo com as regras sintáticas da linguagem formal, temos de colocar o signo de negação em baixo da barra de

${ }^{13}$ Para uma reconstrução, veja Wolff (1995, pp. 245-273).

Manuscrito - Rev. Int. Fil., Campinas, v. 35, n. 1, p. 61-83, jan.-jun. 2012. 
conteúdo. Assim, a negação do conteúdo que p é representada por

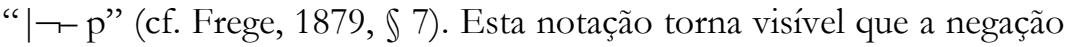
pertence ao conteúdo, não ao ato de julgar. ${ }^{14}$

\section{O Conceito Fregeano de Verdade}

Dada a nossa reconstrução, temos que distinguir dois usos do conceito de verdade, duas maneiras da atribuição da verdade. A primeira é a "atribuição predicativa". Ela consiste sintaticamente na predicação da palavra "verdadeiro", como em

(3) É verdade que a água do mar é salgada.

Vimos que, de acordo com Frege, a atribuição predicativa da verdade é pragmaticamente redundante, ou seja, ela é incapaz de fornecer um proferimento com força assertórica. Além disso, ela é também semanticamente redundante, segundo Frege, porque a sentença (3) e a sentença mais simples

(4) A água do mar é salgada

expressam exatamente o mesmo pensamento. O sentido do predicado "é verdadeiro" não faz nenhuma contribuição essencial para o sentido das sentenças nas quais ele ocorre (cf. Frege, 1983. pp. 140, 251, 271-2).

A segunda maneira é a "atribuição assertórica da verdade". Ela consiste na asserção de um pensamento como verdadeiro e é ligada, sintaticamente, à forma da sentença assertórica. Semanticamente, a atribuição assertórica da verdade também é redundante, porque ela não faz nenhuma contribuição para o conteúdo proposicional das sentenças que proferimos com força assertórica. Mas a atribuição assertórica não é pragmaticamente redundante: a sua função é apresentar conteúdos proposicionais como verdadeiros. Precisamos desta função, por exemplo, para comunicar e para justificar juízos.

Da perspectiva da atribuição assertórica, verdade e falsidade são os critérios que estamos usando implicitamente quando fazemos um

${ }^{14}$ Uma exposição mais detalhada encontra-se em Greimann (2007).

Manuscrito - Rev. Int. Fil., Campinas, v. 35, n. 1, p. 61-83, jan.-jun. 2012. 
juízo. "Julgar" significa sempre "julgar algo como algo", onde o complemento "como algo" indica os critérios usados para realizar o julgamento. Assim, podemos julgar uma ação como moralmente boa ou errada, uma pessoa como culpada ou inocente, um poema como belo, um prato como delicioso, e assim por diante. Mas não podemos julgar algo simpliciter, sem usar nenhum critério.

Em outras palavras, um juízo é uma avaliação que se refere a certos valores. Como a meta da ciência é descobrir verdades, segundo Frege, ele considera verdade e falsidade como os valores (Werte) que aplicamos implicitamente quando fazemos uma avaliação cientifica de um pensamento, ou seja, um juízo científico. ${ }^{15}$ Linguisticamente, este conceito de verdade não é ligado ao predicado "é verdadeiro", mas à forma da sentença assertórica. No caso da sentença "A água do mar é salgada", a forma assertórica expressa que o valor da função $x$ é salgado com a água como argumento é o Verdadeiro.

No escrito póstumo "Logik in der Mathematik" de 1914, Frege diz explicitamente que "[p]ara apresentar algo como verdadeiro, não precisamos de um predicado especial, mas somente [a] da força assertórica com a qual proferimos a sentença" (1983, pp. 251-2). E no fragmento "Logik" de 1897, ele sustenta que "mesmo quando usamos a expressão "é verdadeiro que...", a coisa essencial é realmente a forma da sentença assertórica" (Frege, 1983, p. 140). Por estas razões, não há espaço para duvidar que Frege considera a forma da sentença assertórica como o principal operador de verdade, o meio efetivo para expressar a verdade de um conteúdo na linguagem natural. De acordo com isto, podemos atribuir a Frege uma "teoria assertórica da verdade", segundo a qual a verdade é aquilo que expressamos pela forma da sentença assertórica.

A esta reconstrução Ruffino objetou que, segundo Frege, expressamos pela forma assertórica o nosso reconhecimento da

${ }^{15}$ Cf. p.ex. Frege (1918a).

Manuscrito - Rev. Int. Fil., Campinas, v. 35, n. 1, p. 61-83, jan.-jun. 2012. 
verdade. ${ }^{16}$ Como conseqüência, uma teoria assertórica da verdade parece identificar o ser verdadeiro com o ser tomado como verdadeiro. Tal teoria, porém, não pode ser atribuída a Frege, porque ele sustenta explicitamente que o ser verdadeiro e o ser tomado como verdadeiro são independentes: para que um pensamento seja verdadeiro, não é necessário nem suficiente que tomamo-lo como verdadeiro. ${ }^{17}$

Para levar isto em conta, precisamos reformular a teoria assertórica da verdade da seguinte maneira: verdade é a parte objetiva daquilo que expressamos pela forma da sentença assertórica, ou seja, a parte que podemos entender sem conhecer o sujeito da asserção. Esta reformulação é sugerida pela resposta de Frege à pergunta de Jourdain se ele "considera a asserção ( $\mid-)$ como algo meramente psicológico" (Frege, 1976, p. 126).

\section{A Indicação da Essência da Lógica segundo Frege}

Em "Meine grundlegenden logischen Einsichten" de 1915, escreve Frege:

A palavra "verdadeiro" não faz [...] nenhuma contribuição essencial ao pensamento. Quando afirmo "é verdade que a água do mar é salgada" estou afirmando o mesmo que quando afirmo "a água do mar é salgada". Isto nos possibilita reconhecer que a asserção não está na palavra "verdade", mas sim na força assertórica com a qual a sentença é proferida. Isto poderia nos levar a pensar que a palavra "verdadeiro" não tem nenhum sentido afinal. No entanto, neste caso uma sentença na qual "verdadeiro" ocorre como predicado não teria sentido também. Tudo que se pode dizer é: a palavra "verdadeiro" tem um sentido que não contribui em nada para o sentido da sentença inteira na qual ocorre como um predicado. Mas exatamente por isso é que esta palavra parece adequada para indicar o que é essencial na lógica. Qualquer outra palavra que designasse uma propriedade [Eigenschaftswort] seria menos adequada devido ao seu sentido especial. (Frege 1983, pp. 271-2)

${ }^{16}$ Cf. Ruffino (2006, pp. 38-39).

${ }^{17}$ Cf. Frege (1893, pp. XV-XVI).

Manuscrito - Rev. Int. Fil., Campinas, v. 35, n. 1, p. 61-83, jan.-jun. 2012. 
Para Frege, a lógica é uma ciência geral cujas leis se aplicam a qualquer domínio. ${ }^{18}$ As leis da física, em contrapartida, aplicam-se somente ao domínio dos objetos físicos e as leis psíquicas ao domínio dos objetos psíquicos. Como a palavra "verdadeiro" tem um sentido que não faz nenhuma contribuição essencial para o sentido das sentenças nas quais ela ocorre, ela indica corretamente a generalidade da lógica. Qualquer outro predicado seria menos adequado por causa do seu sentido mais especial. Na medida em que a generalidade da lógica faz parte da sua essência, a palavra "verdadeiro" indica corretamente a essência da lógica. Esse parece ser o raciocínio de Frege no trecho citado. Ele continua como se segue:

Assim a palavra "verdadeiro" parece transformar em possível o impossível, a saber, faz parecer que aquilo que corresponde à força assertórica contribui para o pensamento. E esta tentativa, embora frustrada, ou melhor, exatamente porque ela é frustrada, indica a essência da lógica, e esta parece, de acordo com isso, essencialmente diferente da essência da ética e da estética. Pois a palavra "belo" indica de fato a essência da estética, assim como a palavra "bom" indica a essência da ética, enquanto a palavra "verdadeiro" é efetivamente apenas uma tentativa frustrada de indicar a essência da lógica, uma vez que aquilo que de fato está em jogo não está, de maneira alguma, na palavra "verdadeiro", mas sim na força assertórica com a qual a sentença é afirmada. (Frege 1983, p. 272)

O ponto central desta argumentação parece ser o seguinte: a força assertórica indica a essência da lógica porque o verdadeiro meio lingüístico para apresentar um pensamento como verdadeiro não é o predicado "verdadeiro", mas a forma da sentença assertórica. A linguagem natural é enganadora neste respeito, porque a sua estrutura sugere que o uso do predicado "verdadeiro" é o meio principal. Neste respeito, este predicado faz uma "tentativa frustrada" de indicar a essência da lógica. Ele "parece transformar em possível o impossível”, a saber, realizar a atribuição assertórica da verdade pela atribuição

${ }^{18}$ Cf. Frege (1893, p. XV).

Manuscrito - Rev. Int. Fil., Campinas, v. 35, n. 1, p. 61-83, jan.-jun. 2012. 
predicativa, ou seja, ele "faz parecer que aquilo que corresponde à força assertórica contribui para o pensamento". Quando fazemos a pergunta "É verdade que a água do mar é salgada?", estamos expressando que é verdade que a água do mar é salgada, mas não estamos apresentando o pensamento de que a água do mar é salgada como verdadeiro.

Vimos que a tarefa da lógica é formular leis sobre a justificação de uma verdade por outras verdades que já foram reconhecidas. Desta perspectiva, a lógica não é, no final das contas, uma teoria sobre o nosso reconhecimento de pensamentos, mas uma teoria sobre a justificação do nosso reconhecimento de pensamentos. A palavra "verdadeiro" não é apropriada para caracterizar a essência da lógica, porque o uso do conceito de verdade que é relevante para tal justificação não é a atribuição predicativa da verdade, mas a atribuição assertórica. Conseqüentemente, no final das contas a força assertórica é aquilo que indica a essência da lógica.

Ruffino destaca que a caracterização da lógica pela força assertórica encontra-se exclusivamente em "Meine grundlegenden logischen Einsichten" de 1915. ${ }^{19}$ Este texto não foi publicado por Frege. Além disto, em "Der Gedanke", que foi publicado em 1918, Frege voltou a caracterizar a lógica pela palavra "verdadeiro". Por estas razões, poder-se-ia pensar que a caracterização da lógica pela força assertórica foi uma aberração de curto prazo que Frege corrigiu logo depois.

Esta conclusão, porém, não parece plausível porque Frege termina o seu raciocínio em "Meine grundlegenden Logischen Einsichten" assim:

Então, como é que esta palavra "verdadeiro", embora pareça destituída de conteúdo, não pode ser dispensada? Não seria possível, pelo menos na fundamentação da lógica, evitar esta palavra completamente, visto que ela pode criar apenas confusão? Que nós não podemos fazer isso é devido à imperfeição da linguagem. Se tivéssemos uma linguagem

${ }^{19}$ Ruffino (2006, p.42).

Manuscrito - Rev. Int. Fil., Campinas, v. 35, n. 1, p. 61-83, jan.-jun. 2012. 
logicamente perfeita, não precisaríamos, talvez, mais da lógica, ou poderíamos extraí-la [ablesen] da linguagem. Mas nós estamos longe de estar em tal posição. [...]

Agora, aquilo que indica mais claramente a essência da lógica é a força assertórica com a qual a sentença é proferida. Contudo, nenhuma palavra, ou parte da sentença, corresponde a isso; as mesmas séries de palavras podem ser proferidas com força assertórica em um determinado momento, e em outro não. Linguisticamente, a força assertórica é ligada ao predicado. (Frege 1983, p. 272)

Frege parece considerar o uso da palavra "verdadeiro" necessário para explicitar a essência da lógica, embora este procedimento seja inadequado no final das contas. ${ }^{20} \mathrm{O}$ problema é que pela caracterização da lógica através da força assertórica corremos o perigo de introduzir um elemento psicologista na lógica. Pois, esta caracterização provoca o mal-entendido que o ser verdadeiro de um pensamento consiste no seu ser tomado como verdadeiro. Para evitar este mal-entendido, precisamos usar a palavra "verdadeiro" na explicação da essência da lógica. Esta parece ser a razão pela qual não encontramos a caracterização da lógica pela força assertórica em outros escritos de Frege. ${ }^{21}$

Se a nossa linguagem fosse uma linguagem logicamente perfeita, teríamos um signo próprio para apresentar um pensamento como verdadeiro. Neste caso, poderíamos usar este signo para indicar a essência da lógica. Como, porém, a nossa linguagem não contém tal signo, precisamos usar a palavra "verdadeiro" para este fim. Assim, não podemos explicar o que queremos expressar por " $\mid$ - " na linguagem formal sem usar a palavra "verdadeiro" na meta-linguagem.

A minha solução dos problemas exegéticos colocados pelo trecho citado acima se baseia na distinção entre a palavra "verdadeiro" por um lado, e a barra de juízo “|” e a forma da sentença assertórica por outro. Uma solução alternativa foi proposta por Ruffino no artigo

20 Para um reconstrução mais detalhada desta passagem, veja Greimann (2008, pp. $421 \mathrm{ff}$.)

${ }^{21}$ Uma explanação semelhante encontra-se em Taschek (2008, pp. 378-379).

Manuscrito - Rev. Int. Fil., Campinas, v. 35, n. 1, p. 61-83, jan.-jun. 2012. 
mencionado (2006, pp. 40-42). A sua solução se baseia na distinção entre a palavra "verdadeiro" e a barra horizontal "-", que é interpretada como um predicado de verdade. Recentemente, William Taschek (2008) publicou uma solução semelhante. A diferença entre estas soluções é que Taschek destaca mais o papel normativo que a verdade desempenha na lógica fregeana. A minha intenção aqui era elaborar a minha própria abordagem. Deixarei a comparação com as abordagens do Ruffino e do Taschek para outro trabalho. ${ }^{22}$

\section{Referências Bibliográficas}

ANGELELLI, I. Kleine Schriften. Hildesheim/Zürich/New York: Olms, 1990.

BEANEY, M., RECK, E. Gottlob Frege: Critical Assessments of Leading Philosophers, vol. II, Frege's Philosophy of Logik. London: Routledge, 2005.

DUMMETT, M. Frege: Philosophy of Language. London: Harper and Row, 1973.

. The Interpretation of Frege's Philosophy. Cambridge: Harvard University Press, 1981.

FREGE, G. Begriffsschrift, eine der arithmetischen nachgebildete Formelsprache des reinen Denkens. Halle: Louis Nebert, 1879. Em: G. Frege, Begriffsscbrift und andere Aufsätz̧e, Hildesheim/Zürich/New York: Olms, 1988.

Funktion und Begriff. Jena: Hermann Pohle, 1891. Em: Angelelli (ed) (1990), pp. 125-42.

Jena: Hermann Pohle, 1893. Reprodução: Darmstadt: Wissenschaftliche Buchgesellschaft, 1962.

22 Em Greimann (2007, pp. 48-49), tentei mostrar que a tarefa principal do Horizontal é possibilitar a aplicação dos signos lógicos não somente a sentenças, mas a qualquer nome próprio.

Manuscrito - Rev. Int. Fil., Campinas, v. 35, n. 1, p. 61-83, jan.-jun. 2012. 
FREGE, G. "Der Gedanke. Eine logische Untersuchung”. Beiträge zur Philosophie des deutschen Idealismus 1, 1918a. Em: I. Angelelli (ed) (1990), pp. 58-77.

. "Die Verneinung. Eine logische Untersuchung", Beiträge zur Philosophie des Deutschen Idealismus 1, 1918b. Em: I. Angelelli (ed) (1990), pp. 362-378.

. 1976, Wissenschaftlicher Briefwechsel, vol. I, ed. por G. Gabriel, H. Hermes, F. Kambartel, Ch. Thiel e A. Veraart, Hamburg: Meiner.

vol. I, ed. por H. Hermes, F. Kambartel and F. Kaulbach, seg. edição, Hamburg: Meiner.

GREIMANN, D. "The Judgement-Stroke as a Truth-Operator: A New Interpretation of the Logical Form of Sentences in Frege"s Scientific Language". Erkenntnis, 52, pp. 213-238, 2000.

. Freges Konzeption der Wabrheit. Hildesheim/Zürich/New York: Olms, 2003.

- "Frege's Puzzle about the Cognitive Function of Truth". Inquiry, 47, pp. 425-42, 2004.

. "Frege's Understanding of Truth". Em: M. Beaney e E. Reck (eds.) (2005), pp. 295-314.

“A Negação Fregeana do Número 2". O Que nos Faz. Pensar, 23, pp. 41-51, 2007.

. "Does Frege Use a Truth-Predicate in His Justification of the Logical Laws? ”. Mind, 117, pp. 403-425, 2008.

RUFFINO, M. “O Verdadeiro, o Bom e o Belo em Frege”. O Que Nos Faz Pensar, 20, pp. 27-44, 2006.

TASCHEK, W. "Truth, Assertion and the Horizontal: Frege on 'The Essence of Logic"'. Mind, 117, pp. 375-401, 2008.

WITTGENSTEIN, L. Tractatus Logico-Philosophicus. 1921. Frankfurt am Main: Suhrkamp, 1982.

WOLFF, M. Die Vollständigkeit der kantischen Urteilstafel. Mit einem Essay über Freges Begriffsschrift. Frankfurt am Main: Klostermann, 1995. 